\title{
A imprensa do Paraná nos anos de redemocratização do Brasil - proposta para investimento em pesquisa
}

\author{
José Aparecido Marinho ${ }^{1}$
}

\section{RESUMO:}

Este artigo propõe o investimento, como fonte de estudo e pesquisa, da participação da imprensa paranaense, por meio dos principais jornais do Estado, no processo de construção da história da comunicação, pelo viés do tratamento dispensado à cobertura dos fatos que marcaram a condução da política nacional a partir do final do governo militar, em 1985, abrangendo um período de 20 anos da retomada da democracia no País.

\section{DEFINIÇÃO DO OBJETO E PROBLEMÁTICA}

1985. Após 20 de ditadura, o brasileiro pôde comemorar o fim do regime militar e o início do processo de redemocratização do País, com o retorno de um civil ao cargo de presidente da República. A transição, seus passos e reflexos integraram o agendamento da imprensa nacional, que assumiu maior liberdade, então, para interferir na trajetória política e social da nação.

Ao atuar neste cenário como um importante ator no processo de transformação da sociedade, a imprensa contribuiu para, independentemente da linha editorial e dos interesses nela embutidas, construir a história brasileira. Uma história de conquistas e derrotas, sortes e revezes, em que os leitores e eleitores também puderam desempenhar seu papel com pressuposta maior liberdade.

Conhecer a história da imprensa e analisar o seu discurso enquanto agente social é imprescindível para compreender a intensidade da participação dos veículos de comunicação no processo histórico. No Paraná, em 1984, um ano antes do final da ditadura militar, os jornais publicavam, em suas manchetes, reportagens sobre o início da campanha em favor das eleições diretas para a Presidência. Naquele palco, uma multidão saiu às ruas para reivindicar mudanças no sistema de governo.

Episódios como este ilustram a importância do Estado paranaense na construção da história do Brasil e, assim, enriquecem a relevância de resgatar o trabalho que a imprensa desempenhou em todo o processo.

\footnotetext{
${ }^{1}$ Jornalista (FIEP), mestre em Estudos Literários pela UFPR.
} 
A reabertura democrática no Brasil, em 1985, abriu espaço para a imprensa atuar sem as interferências da censura promovida pelo governo militar nos 20 anos anteriores. Isso possibilitou uma flexibilização no campo da produção jornalística e os veículos de comunicação tiveram condições de ampliar as coberturas e encampar fatos proibidos ou omitidos da história brasileira.

De que modo a imprensa do Paraná - onde foi deflagrada a campanha pelas DiretasJá que culminou com a eleição de um presidente civil - tratou os fatos políticos dos vinte anos seguintes (1985-2005), é a questão a ser respondida, no sentido de ser um instrumento do processo de construção da história política.

Para isso, é importante avaliar em que medida a imprensa paranaense reproduziu a pauta nacional (universal), publicando notícias produzidas pelas agências e assessorias de comunicação públicas e privadas que distribuíam material em larga escala por todo o País. Essa avaliação deve ser contrastada com os momentos em que este estado produziu as matérias de âmbito nacional, que evidencia a participação efetiva na construção da história comunicacional e política do País.

Dessa maneira, é possível avaliar a construção da política paranaense utilizando-se registros de fatos jornalísticos que vêm, ao mesmo tempo, trazer à luz da sociedade material com sustentação científica que evidencie a participação da imprensa paranaense neste processo.

É necessário que o comunicador ou o estudante de comunicação paranaense resgate o que foi notícia e analise o tratamento dispensado pela imprensa, nesses mais de retomada da democracia no País. Um estudo como esse se tornaria um relevante trabalho prestado à sociedade, para ampliação das bases de conhecimento sobre a história da comunicação brasileira e conseqüente formação de massa crítica que seja capaz de reagir em se constatando vícios, comprometimentos, omissões e equívocos que possam ter sido cometidos voluntária ou involuntariamente.

Uma sugestão de proposta seria um foco nos jornais Folha de Londrina e Gazeta do Povo, nas seções de Política, num estudo de duas edições de cada veículo (fevereiro e setembro) durante os anos de 1985, 1986, 1987 e 1988, ano que marca a nova Constituição brasileira.

Este estudo, além de fomentar um debate para a implantação de uma disciplina de âmbito sociológico sobre a prática da imprensa paranaense nos cursos de graduação em jornalismo, buscaria reforçar a importância da comunicação impressa no processo de construção da história. 
Na história da República brasileira, os períodos de democracia sempre se alternaram com os de ditadura, sejam estas declaradas ou disfarçadas. Após a revolução de 1930, foram sete anos de democracia, seguidos por oito de ditadura, dezenove de democracia, mais vinte de ditadura, até a reabertura democrática restabelecida em 1985. A intermitência desses sistemas de governo delineia um cenário heterogêneo da construção do País, em todas as suas complexidades, em que valores, posicionamentos ideológicos, teóricos e práticos da sociedade, tendem a ser guiados por trilhas estabelecidas pelos detentores do poder. Quem manda, define as regras. Os outros, ou se adaptam à ordem ou resistem, colocando-se à mercê de possíveis e prováveis penalizações.

Neste cenário, a imprensa brasileira assume destacado papel na condução da história, quadro notório em inúmeros relatos, pesquisas e textos a respeito do assunto. Isso demonstra a responsabilidade social dos meios de comunicação e dos profissionais responsáveis por abastecê-los, porque o discurso jornalístico, independentemente do tratamento que lhe é dispensado, exerce a função de registrar os acontecimentos e funcionar como agente de transformação social. Segundo Guimarães (2003)

(...) quanto mais efetivo for o compromisso assumido pelo jornalista no
exercício de sua profissão, tanto maior será a contribuição do jornalismo para
que as pessoas desenvolvam uma consciência crítica, o que lhes permitirá
mais facilmente compreender e, com isso, transformar também, a realidade
de que participam. (In: FREIRE, P. \& GUIMARÃES, S., p.134) ${ }^{2}$

O papel da imprensa nesse processo histórico é decisivo, porque a comunicação pública, vista como instrumento para o fluxo de informações coletivas entre fontes e receptores, representa a interface de uma emblemática dialética entre as múltiplas pontas da estrutura social e humana. "Os meios jornalísticos, ao tornarem a sociedade, tendencialmente mais conhecida e reconhecível por ela própria, contribuíram, desde que apareceram, para a concorrência de modificações sociais profundas.” (Idem. p. 121)

No entanto, é difícil mensurar a amplitude do reflexo da atuação da imprensa sobre a sociedade. Souza (2002), ao pesquisar o assunto, não encontrou resposta definitiva à questão. Porém, ressalta a importância da comunicação jornalística na organização da vida cotidiana da população:

\footnotetext{
${ }^{2}$ GUIMARÃES, S. In: FREIRE, P. \& GUIMARÃES, S. Sobre a educação. Vol. 2. São Paulo: Paz e Terra, 2003. p.134.
} 
De alguma forma, as notícias, entre múltiplas outras funções, participam na definição de uma noção partilhada do que é atual e importante do que não o é, proporcionam pontos de vista sobre a realidade, possibilitam gratificações pelo seu consumo, podem gerar conhecimento e também sugerir, direta e indiretamente, respostas para os problemas que quotidianamente os cidadãos enfrentam. (p. 121).

No devido encaixe espacial ou temporal, os veículos de comunicação registram e produzem esta história de lugar privilegiado na construção e condução do processo histórico independentemente de cargas conceituais ou acadêmicas prós ou contrárias a idéias de interesses individuais e ou coletivos.

O jornalismo, pois, com a democracia, é instituição social majoritária. Se deixa de exprimir os ideais da comunidade, de contribuir para a realização das suas causas e solução dos seus problemas e conflitos, de adverti-la dos seus erros e de apontar-lhe os caminhos certos para o êxito dos seus empreendimentos - então falha completamente na sua missão e não se pode queixar do descrédito em que é tido e do desamor que lhe votam os cidadãos. ${ }^{3}$

Agora que o Brasil entra em seu mais longo período democrático, é relevante entender de que modo a imprensa brasileira participou do processo de construção dessa história. Seguindo o entendimento de que as vítimas da ditadura não se concentravam num só ponto geográfico do País, é preciso abranger diferentes e múltiplos espaços, para que as partes se constituam num todo, principalmente levando em conta que, de acordo com SODRÉ, “a história da imprensa é a própria história do desenvolvimento da sociedade capitalista." 4

No Paraná, Estado localizado na região Sul e formado por 399 municípios, a história da imprensa - e escrita pela imprensa - reflete a situação nacional, resguardando suas peculiaridades na estrutura dos veículos, na formação dos profissionais e na produção jornalística. Na época da ditadura, a repressão aqui foi menor $^{5}$ que em outras localidades. Tanto que a capital paranaense, Curitiba, tornou-se referência de fatos determinantes da política brasileira, ao, por exemplo, servir de palco para o lançamento da campanha nacional a favor das eleições diretas para presidente da República. Em 12 de janeiro de 1984, o centro da cidade foi tomado por uma multidão estimada em cerca de 45 mil pessoas, deflagrando o Movimento pelas Diretas-Já. Que depois tomou corpo em todo o País e culminou, no ano seguinte, com a vitória no

\footnotetext{
${ }^{3}$ BELTRÃO, L. Iniciação à filosofia do jornalismo. São Paulo: USP, 1992. p.179-180.

${ }^{4}$ SODRÉ, N. W. História da imprensa no Brasil. Rio de Janeiro: Maud, 1999. p. 1.

${ }^{5}$ Milton Ivan Heller fez um levantamento da repressão e resistência no Paraná, apresentando as denúncias de torturas e arbitrariedades do período.
} 
Colégio Eleitoral de Tancredo Neves para chefiar a Nação, encerrando os 20 anos de governo militar. Tais acontecimentos influenciaram na mudança do sistema político no Brasil e abriram espaço para atuação mais livre da imprensa, que adquiria, deste modo, condições de agir sem interferência da censura.

O jornalismo é o elo que, nos processos sociais, cria e mantém as mediações viabilizadoras do direito à informação. Eis aí o vínculo com o princípio ético universal que deve orientar a moral das ações jornalísticas em função do qual o jornalismo assume a responsabilidade, consciente pelos seus fazeres profissionais. ${ }^{6}$

O jornalismo praticado ao longo de sua história e, principalmente, no período encampado por este estudo, apresenta variáveis em que se destaca uma questão de grande interesse na análise de sua prática: o questionamento quanto à continuidade ou não da censura nos meios de comunicação a partir da redemocratização. A não informação ou a desinformação ${ }^{7}$ maquiam uma das principais atribuições dos meios de comunicação, exemplificadas por BERTRAND:

Ninguém possui conhecimento direto do conjunto do globo. Além de sua experiência pessoal, o que se sabe provém da escola, de conversas - mas sobretudo da mídia. Para o homem comum, a maior parte das regiões, das pessoas, dos assuntos dos quais a mídia não fala, não existem.

Este tema foi abordado na XIII Semana de Estudos de Jornalismo, realizada na Universidade de São Paulo, em 1986, com a participação de jornalistas, professores, historiadores e estudantes. Houve consenso na conclusão de que, apesar do fim da censura "oficial, formal, regimental e organizadas"9, continuaria a existir reprimenda ao jornalismo que, desempenhando sua função, criasse “os constrangimentos ao funcionamento pleno da instituição"10.

Mas uma repressão diferenciada, que o jornalista Alberto Dines cita estar presente em um jornalismo manipulado, generalizador (que trata superficialmente assuntos cujas origens, ignoradas, são polêmicas e fundamentais) e omisso, e que Antônio Félix Nunes cita como regente da imprensa submissa ao "sistema":

\footnotetext{
${ }^{6}$ CHAPARRO, M. C. Pragmática do jornalismo: buscas práticas para uma teoria da ação jornalística. São Paulo: Summus, 1994. p. 23.

${ }^{7}$ BLÁSQUEZ, N. Ética e meios de comunicação. São Paulo: Paulinas, 1999. p. 67-71.

${ }^{8}$ BERTRAND, J-C. A deontologia das mídias. Bauru: Edusc, 1999. p.37.

${ }^{9}$ DINES, A. A censura acabou. Acabou? In: MEDINA, C. (Org.) O jornalismo na Nova República. São Paulo: Summus, 1987. p. 14-54.

${ }^{10}$ Idem.
} 
(...) de repente, a ditadura, que é um remédio para a salvaguarda do sistema torna-se incômoda e passa a atrapalhar, e é preciso se livrar dela. Nesta altura, os militares não querem deixar o poder, eles já se acostumaram. É preciso mobilizar o povo. Então, os meios de comunicação, a grande imprensa que representa o sistema e é formadora de opinião, convoca, dá estímulo ao povo para participar, para tirar a ditadura, para eliminar a censura. Acontecido isto, volta a censura natural, que é a censura do sistema. Esta só pode cair quanto o próprio povo mudar a situação política do país (...). Então, a classe dominante passa a fazer a censura. ${ }^{11}$

Esta ligação da censura à economia ratifica a posição de Herman e Chomski que acreditam que "a mídia serve a quem a controla"12 e à afirmação da aluna de Comunicação do curso de Jornalismo da USP, Elsie Rotenberg, de que o fato dos jornais dos países capitalistas serem empresas privadas, e terem, portanto, o lucro como finalidade, faz com que seja ilusão a crença de que eles existem para veicular notícias. ${ }^{13}$

Destaca-se, ainda neste cenário, o que Chomski e Herman apresentam como as pessoas que "sofreram alguma agressão ou abuso" e tiveram ampla cobertura da imprensa como "vítimas merecedoras", contrapondo-as com as desprezadas "nãomerecedoras", tomando como ponto de partida para determinar o merecimento como a “extensão" e "características da atenção dada e da indignação despertada”"14. Os autores atribuem essa escolha à tendência dos grandes jornais de trabalharem com a sedimentação da política dominante.

Estes posicionamentos servem para apontar as variáveis que devem ser consideradas na análise da participação da imprensa na construção da história, seja como agente transformador social ou como mera reprodutora de discursos de cooptação política, que, invariavelmente, priorizam a manutenção de uma ordem, o status quo. De uma forma ou de outra, a imprensa do Paraná, a exemplo de outras localidades, registrou e produziu a história. Melhor seria - e é isso que este estudo analisará - ter tido os alicerces fincados na trilha de caminhos em que predomina o cumprimento da função jornalística no verdadeiro sentido a que deveriam se propor os veículos de comunicação. "Só existe imprensa livre quando o povo é livre; imprensa independente,

\footnotetext{
${ }^{11}$ NUNES, A. F. A censura acabou. Acabou? In: MEDINA, C. (Org.) O jornalismo na Nova República. São Paulo: Summus, 1987. p. 14-54.

${ }^{12}$ HERMAN, E. S. e CHOMSKI, N. A manipulação do público: política e poder econômico no uso da mídia. Trad. Bazán Tecnologia e Lingüística. São Paulo: Futura, 2003. p. 11.

${ }^{13}$ ROTENBERG, E. O operário da informação vai para as cabeças. In: MEDINA, C. (Org.) O jornalismo na Nova República. São Paulo: Summus, 1987. p. 184-186.

${ }^{14}$ HERMAN, E. S. e CHOMSKI, N. A manipulação do público: política e poder econômico no uso da mídia. Trad. Bazán Tecnologia e Lingüística. São Paulo: Futura, 2003. p. 95-144.
} 
em nação independente - e não há nação verdadeiramente independente em que o seu povo não seja livre.”15

Ao aliar a história contada pela imprensa à história da própria imprensa para compreender a construção da história da sociedade, deve-se levar em conta que se trata de um trabalho além do resgate de datas e de se proceder a recortes no tecido social com vistas a apresentar os jornais paranaenses. O que se pretende é constituir o papel da imprensa na transformação social a partir de seu produto genuíno, que é a notícia. Neste caso, opta-se pelo tratamento à notícia política, devido à relação do tema com os sistemas de governo porque se fala em democracia e ditadura. É pertinente ressaltar que nada impede a extensão do estudo a outros setores abarcados na constituição da estrutura política da nação, intimamente ligados, como sendo os de ordem econômica e de infra-estrutura.

Importante, ainda, é destacar que a imprensa do Paraná possui uma diferença básica em relação a alguns estados. Enquanto em vários destes os grandes jornais, que integram a agenda comunicacional, localizam-se nas grandes metrópolis, aqui a força se divide entre a capital (Gazeta do Povo, em Curitiba), e interior (Folha de Londrina, em Londrina). São 370 quilômetros separando os dois municípios e, além da distância geográfica, há notórias diferenças de pensamento político, culturais e diferenças no modo de se fazer jornalismo.

A Folha de Londrina sempre manteve um conceito de atuação mais crítica, enquanto a Gazeta do Povo é considerada de linha conservadora e mais atrelada aos interesses políticos, governos e organizações. Tais premissas tornam a intenção deste projeto mais atraente, à medida que permitirá uma análise substancial para aferir esta dicotomia.

Um investimento em tal estudo encontraria, na sociedade, suas justificativas e, acrescentaria, para quem se dedicasse a fazê-lo, conhecimento de âmbito histórico, sociológico, jornalístico e político.

\section{REFERÊNCIAS BIBLIOGRÁFICAS}

\footnotetext{
${ }^{15}$ SODRÉ, N. W. História da imprensa no Brasil. Rio de Janeiro: Maud, 1999. p. 9.
} 
ANDREATTO, B. et. Al. Retratos do Brasil - Da monarquia ao Estado Militar. São Paulo: Ed. Política, vol. II, 1984.

ARANTES, A. A. Produzindo o passado. Estratégias de construção do patrimônio cultural. São Paulo: Brasiliense, 1984.

ARENDT, H. Crises da República. São Paulo: Perspectiva, 1999.

BARROZO FILHO, R. Jornalismo sem censura. Curitiba: Ed. doAutor, 1988.

BAUDRILLARD, J. Sociedade do consume. Lisboa: Elfos, 1995.

BELTRÃO, L. Iniciação à filosofia do jornalismo. São Paulo: USP, 1992.

BERTRAND, J-C. A deontologia das mídias. Bauru: Edusc, 1999.

BLÁSQUEZ, N. Ética e meios de comunicação. São Paulo: Paulinas, 1999.

BOBBIO, N. O futuro da democracia: uma defesa das regras do jogo. Rio de Janeiro: Paz e Terra, 1986.

. Estado, governo, sociedade: para uma teoria geral da política. Rio de Janeiro: Paz e Terra, 2004.

CASTELLS, M. A Era da informação: economia, sociedade e cultura. São Paulo: Paz e Terra, 1999.

CÉSAR, D. N. A primavera de Londrina: o despertar de uma cidade contra a corrupção. Londrina: Midiograf, 2001.

CERNEV. J. Liberalismo e colonização - o caso do Norte do Paraná. Rio de Janeiro: Universidade Gama Filho, 1988.

CHAMPAGNE, P. Formar a opinião: o novo jogo político. Trad. Guilherme João de Freitas Teixeira. Petrópolis: Vozes, 1996.

CHAPARRO, M. C. Pragmática do jornalismo: buscas práticas para uma teoria da ação jornalística. São Paulo: Summus, 1994.

DEBORD, G. A sociedade do espetáculo: comentários sobre a sociedade do espetáculo. Rio de Janeiro: Contraponto, 1997.

FERREIRA, J. C. V. O Paraná e seus municípios. Maringá: Memória Brasileira, 1996.

FIGUEIREDO, R. Marketing político e persuasão eleitoral. São Paulo: Konrad Adenauer, 2000.

FIORIN, J. L. (Org.); BARROS, D. L. P. (Org.). Dialogismo, polifonia e intertextualidade. 1 ed. São Paulo: Edusp, 1994. v. 1.

FREIRE, P. \& GUIMARÃES, S. Sobre a educação. Vol. 2. São Paulo: Paz e Terra, 2003.

GHÉHENNO, J-M. O fim da democracia. 2a ed. Rio de Janeiro: Bertrand Brasil, 2003. 
HERMAN, E. S. \& CHOMSKI, N. A manipulação do público: política e poder econômico no uso da mídia. Trad. Bazán Tecnologia e Lingüística. São Paulo: Futura, 2003.

JORGE, F. Cale a boca, jornalista! São Paulo: Vozes, 1992.

KERSTEN, M. S. A. Os rituais do tombamento e a escrita da história. Curitiba. Ed. Da UFPR, 2000.

KUCZIK, M. Conceitos de jornalismo: norte e sul - Manual de Comunicação. São Paulo: Edusp, 2001.

LAGE, N. Controle da opinião pública: um ensaio sobre a verdade conveniente. Petrópolis: Vozes, 1998.

MARINÓSIO FILHO, J. História da imprensa de Londrina: do baú do jornalista. Londrina: UEL, 1991.

MEDINA, C. (Org.). O jornalismo na Nova República. São Paulo: Summus, 1987;

POSSENTI, S. Discurso, estilo e subjetividade. São Paulo: Martins Fontes, 1993.

SCHUMPETER, J. Capitalismo, socialismo e democracia. Rio de Janeiro: Zahar, 1984.

SODRÉ, N. W. História da imprensa no Brasil. Rio de Janeiro: Maud, 1999.

SOUSA, J. P. Teorias da notícia e do jornalismo. Chapecó: Argos, 2002.

THOMPSON, J. B. A mídia e a modernidade: uma teoria social da mídia. Trad. Wagner de Oliveira Brandão. Petrópolis: Vozes, 1998.

URABAYEN, M. Estructura de la información periodistica - concepto y método. Barcelona: Mitre, 1988.

VAN DIJK, T. A. La ciência del texto. Barcelona/Buenos Aires: Paiadós, 1990.

WEBER, M. H. Comunicação e espetáculo da política. Porto Alegre: Ed. UFRS, 2000.

WEBER, M. Ciência e política, duas vocações. São Paulo: Martin Claret, 2001.

WOLF, M. Teorias da comunicação. Lisboa: Ed. Presença, 1994. 